\title{
ENTRE LA LEY Y LA COSTUMBRE. SISTEMAS NORMATIVOS Y GESTIÓN COMUNITARIA Del Agua en Tetela del Volcán, Morelos
}

\author{
Between Law and Custom. \\ Regulatory Systems and Water Commons \\ Management in Tetela del Volcán, Morelos
}

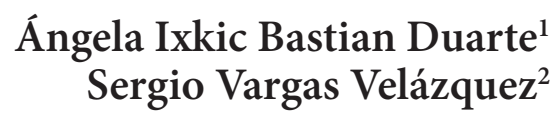

Resumen: Las relaciones establecidas entre las comunidades campesinas e indígenas con el agua forman parte constitutiva de su cultura y su comprensión del mundo. Los grupos sociales transforman su entorno y se lo apropian, estableciendo diversos modos de organización social por el agua que les permiten aprovecharla de forma coordinada y cooperativa. Para lograrlo construyen marcos normativos que regulan su acceso, su distribución y aprovechamiento, mayoritariamente como un recurso de uso común (Ostrom, 2000). La organización social por el agua se articula no sólo con las prácticas agrícolas y el uso consuntivo para las necesidades domésticas, sino de igual manera con diversos aspectos de la vida comunitaria, como es la organización en barrios, la asamblea del pueblo, las relaciones económicas y de poder, así como aspectos simbólicos y el conocimiento construido por generaciones. Aquí se analizan los usos comunitarios del agua en Tetela del Volcán,

\footnotetext{
${ }^{1}$ Dra. en antropología. Profesora investigadora de la Universidad Autónoma del Estado de Morelos. Temas de especialización: antropología de género y temas socioambientales. Correo electrónico: angelaixkic@hotmail.com

${ }^{2}$ Dr. en antropología. Profesor investigador de la Universidad Autónoma del Estado de Morelos. Temas de especialización: organización social y gestión del agua, conflictos por agua, sistemas de riego. Correo electrónico: kuirunhari@yahoo.com.mx Fecha de recepción: 3007 15; Fecha de aceptación: 041215.
}

(cc) EY-NC-ND Páginas 45-73. 
Morelos, y la manera en que se entrelazan con aspectos culturales y las relaciones de poder.

Palabras clave: gestión social, agua potable, agua de riego, pueblos indígenas y campesinos.

Abstract: The relationships established between peasant and native communities with water are a constituent part of their culture and understanding of the world. Social groups transform their environment and appropriate it, establishing various forms of social organization that allow them to benefit from coordinated and cooperative actions among themselves and with other groups. To achieve it, they build regulatory frameworks that control the access, distribution and use of water, mostly as a common resource (Ostrom, 2000). Social organization for water is articulated not only to agricultural practices, but also with various aspects of community life, as is the organization in barrios, economic and power relationships and symbolic aspects and knowledge built over generations. Here we analyze how water commons in Tetela del Volcán, Morelos, is intertwined with cultural aspects and how it has affected the realignment of power.

Keywords: social management, drinking water, irrigation water, natives and peasants.

\section{Introducción}

Los sistemas normativos campesinos e indígenas - también designados como de derecho consuetudinario, indígena, campesino, informal, local o simplemente "usos y costumbres" - son centrales para la reproducción social comunitaria. Se trata de conjuntos de normas tradicionales, usualmente no escritas ni reconocidas por la reglamentación nacional y sin referencia al Estado, pero compartidas por un colectivo, forman parte central de las estructuras sociales y de la cultura de los pueblos y son elemento básico de sus identidades. 
El análisis de los sistemas normativos permite acercarse a las relaciones intracomunitarias, así como a aquellas que las comunidades mantienen con el Estado y otros grupos sociales, pues si bien son propias de los grupos locales, éstas irremediablemente interactúan en distintos planos con el orden político nacional, generalmente de manera asimétrica.

Estos sistemas pueden y suelen reglamentar también distintos aspectos de las relaciones de la comunidad con el entorno natural; no son estáticos sino históricos, y se transforman debido tanto a factores contextuales como internos (Boelens, Zwarteveen y Roth, 2005).

Con respecto al agua, en nuestro país se ha documentado que los sistemas normativos campesinos e indígenas incluyen el establecimiento de derechos y obligaciones relacionadas al uso del líquido, con un importante énfasis en la regulación del agua para riego, ya que se trata generalmente de comunidades agrícolas que defienden sus recursos hídricos frente a organismos gubernamentales o a otros agricultores (Palerm, 2005; Martínez 2007; Palerm y Martínez, 2007), y más recientemente se ha ampliado la investigación de este manejo campesino e indígena del agua para consumo humano, en el que se incluyen también numerosos conflictos por el acceso y aprovechamiento del agua bajo marcos normativos locales (Rodríguez, 1995; Ennis-McMillan, 2001; Galindo y Palerm, 2007; Sandoval, 2011; López-Villamar et al., 2013).

Los estudios sobre el riego, como la gestión local o social del agua, han definido el derecho al agua como el reclamo o exigencia de un grupo social para beneficiarse de determinado sistema de riego o de agua potable, con base en las formas propias de organización y gestión. A diferencia de distintos estudios previos, ahora insertan el manejo comunitario en una argumentación "comunalista", en la cual la comunidad es presentada sólo como receptora de las prácticas depredadoras del medio ambiente del capitalismo global cuando, como lo señala Ostrom, esto es sólo una de las posibilidades, concurriendo más bien distintas combinaciones posibles, una de las cuales pueden ser los marcos normativos y organizaciones comunitarias que también producen deterioro ambiental. El comunalismo se plantea como una tercera vía en la que la tradición indígena comunitaria se encuentra fundamentada 
en el territorio comunal, el trabajo comunal, el poder político comunal y la fiesta comunal; mientras que los elementos auxiliares de la vida comunal serían: el derecho indígena, la educación indígena tradicional, la lengua tradicional y la cosmovisión (Rendón, 2003), llegando incluso, como hacen Laval y Dardot (2014), a plantearlo como la alternativa al capitalismo y sus prácticas extractivistas y de despojo.

Estas formas comunitarias de gestión del agua tienen un fundamento cultural y se vinculan a aspectos identitarios. La capacidad de los grupos sociales de administrar el agua y los otros bienes naturales según sus propios criterios, así como de tomar decisiones sobre su territorio - el espacio sobre el que estos grupos despliegan sus formas de organización y marcos normativos comunitarios- es fundamental para la reproducción de su identidad, sea esta indígena o campesina sobre un espacio en que despliegan sus determinaciones, es decir, un territorio. La pérdida de dicho poder de decisión y de control puede llevar a su debilitamiento frente al Estado nacional o frente al mercado; a través del surgimiento o profundización de las desigualdades al interior del grupo que ponen en riesgo sus instituciones sociales.

Antes de ser recurso o un bien que representa riqueza, el agua es un activo social en sentido amplio, que representa el patrimonio de la sociedad que se beneficia de ella, sea simplemente a través de las condiciones ambientales que crea a través de sus funciones ambientales y los ecosistemas que se desarrollan a partir de su disponibilidad natural, o bien como un recurso para la sociedad bajo una diversidad de formas, sea como un activo social o un activo económico (Aguilera, 2003). Muchas perspectivas económicas sólo conciben el activo como activo económico, sin considerar incluso su especificidad como "recurso fugitivo", tal como fue definido por Ciriacy-Wantrup (Aguilera, 1988) y tratado por Ostrom (2000) como una condición para su aprovechamiento como recurso de uso común.

En las comunidades campesinas e indígenas, el manejo del agua es predominantemente comunitario, esto es, el agua es un recurso de uso común (Ostrom, 2000), en el cual también se le incorporan, influyen o enmarcan formas de poder local y organización social propia de estos grupos. Es importante aclarar que las formas de gestión del 
agua como recurso de uso común no es privativa de campesinos e indígenas. Estas formas también pueden existir entre agricultores que participan en las asociaciones de usuarios de módulos en los distritos de riego del noroeste, en donde predomina la agricultura comercial de exportación con grandes empresarios agrícolas. El carácter comunitario del agua está fundamentado en las formas institucionales anidadas que enmarcan la gestión local del agua. En muchas localidades persisten procesos colectivos que se realizan a través de asambleas de pueblo, procesos de toma de decisiones a partir de la organización de barrios, grupos de vecinos en torno a una fuente para uso doméstico o de riego, las cuales reproducen procesos de toma de decisiones, establecimiento de sanciones o simplemente las reglas de acceso y distribución, con base en su pertenencia a la colectividad.

La antropología jurídica, especializada en el estudio de los aspectos culturales de estos sistemas normativos, centra el análisis de una de sus líneas de investigación en las tensiones entre los derechos individuales y colectivos; otras exploraciones de esta perspectiva han recorrido la documentación y reflexión en torno a la multiplicidad de sistemas normativos y las formas en las que coexisten. En el presente artículo, retomando algunas motivaciones de la antropología jurídica, se busca reflexionar acerca de ciertas expresiones de la diversidad cultural en las relaciones sociales en torno al agua y a las formas en las que se ha dado cuenta de dicha diversidad.

\section{La gestión gubernamental del agua en México}

Desde 1888 y durante la mayor parte del siglo XX, la gestión estatal del agua en México estuvo marcada por un creciente intervencionismo gubernamental y por la centralización de todas las decisiones en el gobierno federal (Aboites, 1998). En la Constitución Política de 1917 se estableció como autoridad del agua al gobierno federal, excluyendo no sólo las formas comunitarias de gestión, sino incluso a gobiernos municipales y estatales. Dicho marco jurídico le otorgó a la Nación la propiedad de los recursos hídricos y, bajo este supuesto, al gobierno federal, como representante de la misma, le dio toda la autoridad sobre ellos, anulando formalmente cualquier derecho local o consuetudinario 
al agua. Sin embargo, el Estado no tuvo nunca la capacidad de controlar todos los sistemas de abastecimiento de agua potable ni de riego, ni de satisfacer la demanda en todas las regiones del país y, como se sabe, tampoco logró regular apropiadamente los derechos de agua. Uno de los muchos ejemplos de esto es el sobreconcesionamiento de derechos de agua en que se encuentran regiones hidrológicas como LermaChapala, Río Bravo, Balsas, Valle de México, entre otras, además de los principales acuíferos del país.

En la década de 1990 se reorienta la política pública del agua, al reconocer la crisis del modelo de gestión centralizada orientada para garantizar la oferta del desarrollo. Se publica la Ley de Aguas Nacionales de 1992, en la cual la autoridad federal pretendió incorporar a la sociedad en la gestión del agua mediante una figura de representación de usuarios, con funciones consultivas y bajo un esquema de participación que reproduce el ideal de la negociación corporativa: el menor número posible de integrantes para negociar más fácilmente en instancias cuya agenda está bajo control de funcionarios federales. A esta representación en consejos, comisiones y comités de cuenca para aguas superficiales, y comités técnicos de aguas subterráneas para acuíferos, únicamente logran acceder los grupos de interés mejor organizados. Se propone la creación de comisiones estatales de agua y se fortalece el papel de los municipios en la gestión del agua potable.

Desde entonces se han implementado políticas públicas de regularización de derechos de agua, pero un número significativo de usuarios continúa sin cumplir con los requisitos. También se han impulsado incentivos para que los sistemas de pequeño riego y los de manejo comunitario del agua sean regulados por alguna instancia gubernamental, como ha sido la creación de asociaciones civiles que agrupan unidades de pequeño riego, como se ha hecho en las de mayor tamaño en el norte del país, con el fin de ser sujetas de crédito y control por parte de Conagua, y como ya se intentó en Tetela de Volcán, pero con el fin de regularizar las extracciones irregulares a través de mangueras. Pero, a la fecha, subsiste la resistencia de agricultores campesinos e indígenas en muchas partes del país, así como la incapacidad operativa gubernamental, en sus distintos niveles, para lograrlo plenamente. 


\section{Diversidad cultural y la gestión del agua}

A principios del siglo XXI, ante la presión de un fortalecido movimiento indígena y de instancias multilaterales como la ONU y OEA, el Estado mexicano, con Vicente Fox a la cabeza, incorporó al discurso oficial conceptos que habían sido utilizados con anterioridad por el movimiento indígena, como derechos indígenas, diversidad étnica y pluriculturalidad, para explicar incluso la consolidación nacional. Las políticas multiculturales que sustituyeron al indigenismo, y que en nuestro país tienen un momento importante en la reforma constitucional de 2001, pueden leerse como otra estrategia de asimilación, ante el fracaso de políticas de aculturación que dominaron la segunda mitad del siglo XX. A pesar de que hoy la Constitución Política reconoce la pluriculturalidad del país, no pocas expresiones concretas de la diversidad quedaron fuera del reconocimiento oficial. En el caso de las formas comunitarias de gestión del agua, no existen referencias a instituciones sociales, económicas y políticas propias de los pueblos indios y campesinos en la Ley de Aguas Nacionales, a pesar de que en otros apartados de la legislación ambiental esto sí ocurre (Ávila, 2007). A las formas comunales de distribución y uso del agua no se le concede importancia proporcional al volumen de población que administra por esta vía el agua potable y la de riego que consume. Tampoco existe alguna declaración específica sobre la agricultura campesina y su uso del agua. No todas las leyes estatales de agua consideran a los sistemas comunitarios de agua potable como parte de su gestión del agua.

El multiculturalismo es para Hale (2006) parte del proyecto cultural del neoliberalismo y ha consistido en la incorporación de algunas figuras indígenas al aparato estatal y en una apertura relativa a la mayor participación política de sus comunidades, mientras se levantan nuevas barreras a las aspiraciones transformadoras del movimiento indígena y se neutralizan sus contenidos políticos. Es decir, implica la adopción, por parte de los estados, de un nuevo discurso que reconoce los derechos indígenas y su importancia para las democracias contemporáneas, sin que esto signifique una transformación de las condiciones de vida de la mayoría de los indígenas. 
El indigenismo nace de la necesidad del estado mestizo resultante de la revolución de 1910 de conformarse como nación moderna, con una historia y con una identidad. El mestizaje fue la alternativa para construir esa nueva nación al grado de proclamar la superioridad de las razas mixtas, de la "raza cósmica" de José Vasconcelos. Mestizaje e indigenismo conformaban el programa cultural del nuevo Estado mexicano en relación con los indios. El objetivo era el blanqueamiento progresivo y la disolución de las particularidades étnicas, fundamentalmente en las décadas de los 30 y 40, cuando las políticas gubernamentales frente a las poblaciones indígenas estaban encaminadas a construir una identidad nacional mestiza y homogénea, considerada necesaria para alcanzar la modernidad (Hernández, 1995). Lázaro Cárdenas no aludía a las diferencias biológicas o a trazos culturales para explicar la desigualdad, sino a un proceso histórico de lucha de clases, pero igualmente buscaba la integración nacional mediante la homogeneización social y política. Las distintas formas que el indigenismo presentó durante el siglo pasado coinciden en el interés por diluir las identidades indias en una única identidad nacional a través del mestizaje (Gall, 2001). Los indigenistas revolucionarios, sin desearlo, heredaron a las instituciones federales que nos han gobernado hasta hoy una carga ideológica profundamente racista.

La administración gubernamental, por otra parte, busca formas homogéneas de gestión basadas en aspectos técnicos y burocráticos, así como en principios de eficiencia económica. Esto no significa que en grandes sistemas de riego o sistemas municipales de agua potable no se encuentren importantes concentraciones de población indígena y campesina, o que ambas formas organizativas no se traslapen, todo lo contrario, esto ocurre constantemente.

En casi cualquier pequeña localidad es posible encontrar una pluralidad de organizaciones que aprovechan el agua bajo marcos normativos muy diversos, distintos a los oficiales. Un ejemplo documentado es el del municipio de Temoaya, Estado de México (Estrada y Franco, 2004), donde se puede identificar un organismo operador vinculado con la respectiva comisión estatal del agua, cuyas competencias y jurisdicciones están establecidas entre la ley federal, la 
estatal y el ordenamiento municipal. Sin embargo, existen y son más importantes los comités locales de agua potable, los cuales no dependen administrativamente del gobierno estatal ni municipal. Se reconocen como parte de una estructura tradicional autónoma que no permite la intervención o participación de personas ajenas a la localidad.

Los comités más numerosos son aquellos formados en las pequeñas localidades rurales, bajo sus propias instituciones, por lo que aparece una combinación de situaciones. Algunos de ellos se vinculan con la organización de la propiedad de la tierra, sea ejidal o comunal. Otros existen de manera independiente al manejo de la tierra, pero vinculados con el sistema de cargos religiosos, en tanto que quien llega a ser encargado del sistema local del agua requiere pasar por una serie de requisitos como el haber servido en cargos religiosos o en la organización de los barrios, como son las mayordomías. En estos sistemas generalmente existe un pozo, manantial o pequeńa infraestructura a partir de la cual se organizan para conservarla y distribuirla. También existen otros sistemas aún más pequeños, dependiendo de las características del recurso hídrico y de sus usuarios. En la región de los Altos de Morelos hay numerosos sistemas en torno a mangueras y cajas de agua, jagüeyes y bordos, así como aquellos organizados a partir del abastecimiento por pipas, los cuales presentan importantes variaciones entre sí. Lo mismo se puede documentar en entidades con mayor presencia indígena, como Guerrero, Oaxaca, Chiapas o Michoacán (Ávila, 1996).

Con respecto al riego sucede algo similar. El riego en México está dividido en gran irrigación, conformado actualmente por 86 distritos de riego, los cuales están bajo supervisión del gobierno federal vía programas de distribución de agua, tarifas y sistema de financiamiento, apoyos productivos, entre otros. La población indígena y campesina ubicada ahí, explícitamente reconocida, incluye los casos de Colonias Yaquis, varios módulos de riego de río Mayo, río Fuerte, Tikul, Valle de Mezquital, Tepetitlán, Tehuantepec, áreas importantes de los distritos del centro y sur principalmente.

En contraste, existen más de 40 mil sistemas de pequeña irrigación —no se sabe su número con precisión-, históricamente fuera de la supervisión directa de entidades gubernamentales, manejados por 
sus propios usuarios. Un número importante de estos sistemas está clasificado como "controlados", ya que mantienen algún vínculo con las autoridades del agua, ya sea porque cuentan con infraestructuras cuyo origen estuvo en algún programa gubernamental, o bien por manejar infraestructura que requiere alguna intervención gubernamental; los que no son supervisados resultan de los que no se sabe mucho y sobre los cuales tampoco se tiene control.

No se conoce el número total y ni se sabe mucho acerca de la diversidad organizativa de estos sistemas. Algunos asumen un manejo privado y bajo reglas de mercado del agua, ya que predominan formas de producción plenamente vinculadas al mercado, generalmente con base en el monocultivo, la compra venta de agua —más en el caso del agua subterránea contigua a zonas de riego con agua superficial-; pero incluso ahí existen formas del manejo del agua como recurso de uso común, bajo marcos normativos locales. Los sistemas de manejo comunitario de aguas superficiales son dominantes. Los agricultores que acceden al riego en estos sistemas se encuentran organizados de forma autogestiva (Palerm y Rivas, 2005).

Las relaciones entre el Estado y los pueblos campesinos e indios en cuanto al acceso y aprovechamiento del agua varían a lo largo y ancho del país. La burocracia gubernamental no tiene una contabilidad oficial de los sistemas operados de acuerdo con formas locales pero logra identificar los más importantes puntos de confrontación entre la gestión social y la gubernamental. Estas tensiones han llevado a que las autoridades reconozcan algunas formas de organización local; las articulaciones entre estas últimas y la burocracia han quedado, generalmente, a cargo de municipios o cuando más de las comisiones estatales de agua. En algunas leyes estatales de agua se menciona y llegan a clasificar los comités locales de agua potable principalmente, ya que las leyes estatales se focalizan principalmente en el agua potable, o en su caso se reconocen a las asociaciones de usuarios de riego cuando la misma ley estatal incorpora aspectos de gestión de cuencas y ordenamientos hidrológicos como sucede con la Ley del agua y gestión de cuencas para el estado de Michoacán. Aunque la reforma al artículo 115 constitucional, que data de 1983, le dio al municipio las funciones 
de operador de agua potable y saneamiento, la asignación del líquido es dada por la autoridad federal, y en muchos casos sólo abarca las cabeceras municipales, dejando al entorno rural a sus propias formas de autogestión.

La gestión social del agua está generalmente vinculada con otras formas de organización de los pueblos, como las mayordomías, las estructuras barriales u otras configuraciones locales. La escala espacial en la que existen y se movilizan generalmente no rebasa lo que sus integrantes pueden "caminar en un día" e incluyen a las personas con quienes éstos se relacionan cotidianamente. Las diferencias de escalas, motivaciones y maneras de organizarse marcan las contradicciones entre los marcos normativos locales y los nacionales.

En varios sistemas normativos campesinos prevalece el derecho local al agua, basado en la definición del propio territorio, y en ocasiones, delimitado a partir de las formas de acceso o posesión ejidal o comunal de la tierra. Muchos pueblos indios y mestizos consideran que el agua que fluye por sus territorios les pertenece, al estar ya reconocido su derecho a ese territorio por la autoridad federal a través del título ejidal o comunal. Esto se expresa en la existencia de un marco normativo propio, generalmente no reconocido legalmente por las autoridades formales (Roth et al., 2005). En este contexto, las decisiones del gobierno federal, estatal o municipal son reinterpretadas o mediadas por distintos sectores de la comunidad.

\section{Tetela del Volcán: entre la ley y la costumbre}

Tetela del Volcán es una localidad ubicada en la región conocida como los Altos de Morelos, y es cabecera del municipio del mismo nombre, hace frontera con los estados de México y Puebla, cuenta con aproximadamente diez mil habitantes. Es parte del sistema formado por la cordillera del volcán Popocatépetl, cuya cima llega a los 5,452 metros, y del cual se forman numerosas barrancas, resultado de las corrientes de agua y de los deshielos. Los agricultores de Tetela aprovechan las aguas superficiales y las numerosas resurgencias a lo largo de las principales barrancas que corren de norte a sur, ubicándose principalmente en las que conforman la microcuenca del río Amatzinac, conocida por los 
múltiples e intensos conflictos por sus aguas desde hace más de un siglo (Vargas 2001; Valladares, 2003; Palerm y Rivas, 2005). El río Amatzinac es una barranca profunda que nace en las laderas del volcán Popocatépetl en el municipio de Tetela del Volcán a 3,900 msnm, y en su trayecto hacia el sur recorre los municipios de Zacualpan, Temoac, Jantetelco, Jonacatepec y Axochiapan del estado de Morelos, con una longitud de $60 \mathrm{~km}$. Es afluente del río Nexapa o Atoyac, uno de los principales tributarios del río Balsas (Conagua, 2009).

El uso del agua en las comunidades rurales ha implicado históricas disputas por su control, así como el desarrollo de conocimientos específicos y de técnicas, a veces ecológicas y otras no. En Tetela del Volcán se observan dos formas comunitarias de uso y gestión del agua al margen de la administración gubernamental: las cajas de agua, para uso doméstico, y el sistema de mangueras para uso agrícola. En este caso, esto no alude a relaciones armónicas con la naturaleza o siquiera sustentables. Esta primera exploración apunta al aprovechamiento del agua por los sectores ya de por sí pudientes o con un mayor capital político.

Aunque existen antecedentes en cuanto a sistemas de riego campesino en la zona, por ejemplo el sistema de la Duraznotla Las Ventanas, cuya existencia se puede documentar desde hace casi un siglo (Guzmán, 2010), la experiencia de la mayoría de los agricultores de Tetela no va más allá de la década del 70 u 80 del siglo pasado.

En los años 80, durante la gubernatura de Lauro Ortega (19821988), se impulsó la agricultura de riego comercial, bajo cubierta y a cielo abierto. En la cuenca alta del río Amatzinac se implementaron proyectos productivos de viveros y el cultivo de frutales, generándose una mayor demanda de agua y tierra para la producción. Se desplazó la agricultura de temporal y subsistencia en pequeñas parcelas y traspatio, y se reactivaron viejas organizaciones de riego que ya estaban venidas a menos. Las nuevas tierras de riego en Tetela utilizarían el agua del río Amatzinac, ya disputada décadas anteriores, para lo cual recibieron del mencionado gobernador las mangueras que ahora surcan grandes trayectos, de hasta de 22 kilómetros, y forman parte del paisaje local. En esas condiciones se dio la expansión del riego. 
En la comprensión de los agricultores de Tetela, el agua que pasaba por sus tierras les pertenecía, tenían derecho a tomarla. Partiendo de esta certeza, los agricultores aplicaron al nuevo sistema de mangueras, las reglas comunitarias previamente existentes para el manejo del agua, y esto originó las históricas tensiones entre Tetela, que se encuentra en la cuenca alta del río Amatzinac, y las comunidades localizadas en la cuenca baja, primero, y luego con la parte media (Vargas, 2001; Palerm y Rivas, 2005).

Para inicios de la década pasada, los agricultores de Tetela estaban extrayendo 850 l/s de la barranca de Amatzinac, en lugar de los 154 1/s que tenían autorizados por la dotación de 1951 (Palerm y Rivas, 2005). La justificación era el derecho comunitario al agua por el cual no se le puede negar el acceso a ningún miembro de la comunidad que ponga más mangueras: es su derecho, hasta ahora, ya que toda el agua que pasa por su territorio pertenece a la comunidad.

A partir de entonces, la nueva dinámica socioeconómica incrementó la extracción del agua. Como consecuencia se dejó sin agua a municipios como Zacualpan de Amilpas, Temoac, Jantetelco, Jonacatepec y Axochiapan. Este conflicto implicó la movilización de las poblaciones afectadas, especialmente de Zacualpan de Amilpas (Espinosa, 2005), las cuales encontraron la resistencia conjunta de Tetela y Hueyapan — del mismo municipio y contiguo a Tetela, pero con el cual se mantiene otra disputa, por un manantial- y que defendían su derecho al agua.

Tetela justificó su derecho al agua con la documentación agraria que certifica la propiedad comunal y ejidal —existe además un número reducido de pequeños propietarios.

El conflicto por el bosque es también añejo (Arias y Bazán, 1979), y a la fecha se encuentra vigente; actualmente los contrincantes son los ejidatarios y comuneros de los pueblos adyacentes, como Ecatzingo, perteneciente al Estado de México.

De esta manera nunca hubo una concesión de Conagua que avalara las extracciones. Lo que sí se ha dado son numerosos conflictos para su regularización desde la década de 1990 (Vargas, 2001; Valladares 2003), a través de un proyecto de ordenamiento de la cuenca, la creación de una unidad de riego con un perímetro definido por el gobierno federal 
a través del Organismo de Cuenca del Río Balsas (UACH/Conagua, 2008), o bien a través de la construcción de infraestructuras y la asignación de un volumen a las mismas.

El acceso al agua impulsó un patrón de cultivos que rápidamente insertó a los agricultores locales en un circuito comercial amplio. Primero a través del durazno, y actualmente del aguacate, además de otros cultivos. Pero no han dejado de ser campesinos, mantienen una estrategia productiva mixta, con cultivos locales como maíz y chayote, además de los cultivos comerciales. El tamaño de las unidades de producción impide que se conviertan en grandes empresarios ya que no rebasan la hectárea en promedio - aunque la mayoría de ellos trabaja superficies menores que se cuentan en algunas "tareas", es decir, la décima parte de una hectárea.

\section{La organización social y su vínculo con la gestión social del agua}

Los habitantes de Tetela del Volcán han tenido, a lo largo de la última centuria, un proceso de creciente vinculación formal con el Estado mexicano que ha implicado la adopción de la figura de municipio y la adaptación a todas sus derivaciones organizativas (Arias y Bazán, 1979; Reyes 2011). Las formas comunitarias se han debilitado pero no han desaparecido, algunas de ellas han tenido variaciones importantes, como la asamblea del pueblo, figura política central del funcionamiento colectivo y del poder local. Reyes (2011) menciona situaciones en las que la asamblea llama a rendir cuentas incluso a los presidentes municipales, u otras en las que si algún habitante reconocido es convocado y no asiste se le sanciona con una multa, o bien se le impide la salida del pueblo. Actualmente esta instancia es dominada por los agricultores ejidatarios frente a los pequeños propietarios y comuneros, probablemente debido a que han podido insertarse mejor en la economía regional así como utilizar las relaciones con los gobiernos federal, estatal y municipal propiciadas por el incremento de los cultivos comerciales. Varias disputas por el agua se han dirimido en la asamblea del pueblo.

Se mantiene la organización por barrios, y éstos a su vez se encuentran divididos por manzanas o cuadrillas. En cada uno de los cinco barrios 
persisten las mayordomías, compuestas por los visperero, diputado, mayordomo y "clecoquis", cuyas funciones centrales tienen que ver con el ciclo ritual. Con el crecimiento demográfico experimentado en la localidad en los últimos años y con la expansión de la demanda de agua potable ha sido necesaria la instalación de una red de agua por parte de un Organismo Operador - órgano paramunicipal que ha sido incapaz de cubrir la demanda-_, también se ha implementado el llamado comité de barrio, el cual consta de un presidente, tesorero, secretario y dos vocales, así como de un comité general de pueblo al cual se le conoce como comité de agua (Reyes, 2011: 17). De esta manera, el manejo del agua a nivel local está fuertemente vinculado con las formas de organización social existentes.

En Tetela del Volcán el uso comunitario del agua ocurre fundamentalmente a través de dos figuras: la organización de manguereros, que se encarga del sistema de mangueras que traslada el agua desde los veneros del volcán hasta las tierras de cultivo, y la organización de cajas de agua, que administra el agua potable proveniente de nacimientos más cercanos a la comunidad; en este caso existe además el Organismo Operador de Agua Potable y Alcantarillado como órgano paramunicipal, como ya se comentó. En ambos casos se trata de organizaciones que se entretejen con las estructuras comunitarias tradicionales y, en su mayoría, no cuentan con ningún título de concesión de agua por parte de la Comisión Nacional del Agua.

\section{Las cajas de agua}

La red de agua potable llegó a Tetela en 1988 por iniciativa del gobierno estatal (Guzmán, 2012), y formalizó su organización once años después, en 1999. A pesar del tiempo transcurrido desde entonces, la red pública no ha logrado satisfacer la totalidad de la demanda doméstica. Por esta razón han persistido formas de autoabastecimiento y de organización social para acceder al agua de las barrancas, generalmente asociadas al uso del agua tanto para riego de huertos de traspatio como para consumo humano.

A mediados de la década del 1960, los pobladores comenzaron a construir las primeras "cajas de agua", que son estructuras de cemento 
que cubren un nacimiento o fuente, y una tubería que traslada el agua desde ese lugar hasta las casas; actualmente hay por lo menos 15 cajas. A veces el líquido se distribuye en contenedores intermedios, y otras va directamente a la zona habitacional. Según se explica en entrevistas realizadas en la localidad, la primera caja fue la de Atzonco, construida para un grupo de aproximadamente 80 familias, que también proveía a dos escuelas y a una clínica. Un integrante de ese grupo explica:

Parece que - la de Atzonco- es la caja de agua más antigua. El manantial es un poquito pequeño, para aprovechar el agua, había que hacer una caja de agua, allí se pusieron todas las tomas. Las cajas son algo importante del pueblo porque no todos en él tienen el agua - del municipio- (entrevista realizada en Tetela del Volcán, Morelos, el 25 de septiembre de 2014).

El trabajo en torno a las cajas propició que la organización comunitaria orientada a la gestión del agua, que ya existía, se fuera volviendo más compleja e incorporara prácticas como la elección de representantes y de administradores de fondos comunes. Se construyeron varias cajas, cada una, inicialmente, utilizada y administrada por una familia ampliada o un grupo pequeño de familias relacionadas consanguínea o ritualmente.

En torno a las cajas de agua hay un ciclo ritual cuya marca más visible es el día de la enflorada, que ocurre los primeros días de mayo, con motivo del día de la Santa Cruz, que es el 3 de dicho mes, aunque no todos los grupos enfloran la cruz de su caja en esa fecha. La ceremonia consiste en "vestir" una cruz con flores, que pueden ser de distintos tipos, colores y tamaños, y colocarla en el nacimiento de agua o sobre la caja de cemento que la cubre. Los integrantes del grupo, nińos y adultos, se dan cita en el manantial, llevan la cruz con flores y rezan una serie de oraciones colectivamente, guiados por la madrina o el padrino de la caja; finalmente, comparten algo de comer, donado por los padrinos. Sobre esto habla otro integrante del grupo de Atzonco: 
Según las creencias de nosotros, se enflora la cruz para que no se acabe el agua ... es tradición. Me tocó hablar con muchos ancianos, hacían enfloradas en el cerro, no sólo la cruz, ponían cazuelas de mole, de comida, rezaban a Dios por el agua. Los campesinos pronostican cuándo se van a retrasar las lluvias, empiezan a hacer esas actividades el 3 de mayo, enflorar, rezar. Aquí en el pueblo hasta en las casas hay una cruz enflorada (entrevista realizada en Tetela del Volcán, Morelos, el 5 de mayo de 2013).

Algunos de los grupos de beneficiarios de las cajas de agua se han ido ampliando, o transformando, y en este proceso los rituales también se han modificado. Los grupos que cuentan con integrantes evangélicos ya no enfloran las cajas. En la región existe la creencia de que para tener agua suficiente cada año hay que "cultivarla" a través de estos rituales.

A pesar de los cambios que puedan tener los grupos y comités, la gestión de las cajas se mantiene fundamentalmente entre las mismas familias, y generalmente se ingresa por herencia. Cuando alguien sale, no se integran nuevas personas de forma automática, sino que se calcula que el agua utilizada anteriormente por quien se va será repartida entre quienes permanecen. Los integrantes del comité, que son un presidente, un secretario, un tesorero y vocales, se cambian cada tres años, en asamblea. Éstas se realizan cada dos o tres meses, dependiendo de las necesidades del grupo y del mantenimiento de las cajas; y aunque los cargos del comité pueden, y con frecuencia son, ocupados por mujeres, en las asambleas suelen participar los padres de familia, y en ausencia asisten las esposas, hijos o hijas. Cada familia cuenta con un voto. Cada caja tiene una madrina y un padrino, y éste es un nombramiento de por vida.

El comité es responsable de la organización comunitaria para las faenas de mantenimiento del sistema y para las fiestas, las cuales constituyen o reflejan el eje de la organización. La fortaleza de los vínculos sociales parece disminuir la importancia de las normas y sanciones, que también existen, y da un mayor valor a la reciprocidad, la cual se hace robusta con la idea de un reparto equitativo de agua y 
de las labores requeridas para la operación del sistema de cajas en la localidad.

Las sanciones pueden ser de varios tipos, económicas, en trabajo comunitario o de suspensión del servicio. La primera, equivalente a jornales de trabajo por día, que impuesta de forma reiterada puede llevar a la expulsión del grupo. Se sancionan principalmente las inasistencias a las reuniones del comité o a las asambleas, espacio en el cual se legitiman las acciones del grupo, y a las faenas de mantenimiento del sistema. E igualmente es sancionable y muchas veces más reprobable, la no asistencia a jornadas de defensa de propiedad del recurso, que por lo general se realizan en el sitio de captación (Guzmán et al., 2012).

\section{Las mangueras}

Esta tecnología de riego consiste en una serie de mangueras de PVC hidráulico que va desde la corriente del río Amatzinac o desde los manantiales y nacimientos de agua ubicados en las laderas del Popocatépetl hasta las parcelas agrícolas. Las mangueras recorren varios kilómetros, en algunos casos llegan a 28 , a veces a ras de tierra y muchas otras colgadas hasta 300 metros de altura, sostenidas con cables de acero.

Los manguereros están organizados en grupos; regularmente, cada grupo administra el agua proveniente de una fuente - manantial, escurrimiento o incluso del río mismo-. Cada grupo cuenta con entre 11 y 105 integrantes; se estima que existen unos 140 grupos para 1,200 hectáreas, con alrededor de 800 agricultores con riego (Reyes, 2011), aunque ellos mismos no saben exactamente cuántos son por su resistencia a ser contabilizados.

Cada grupo tiene una vida organizativa independiente, es decir, realiza sus actividades siguiendo el ritmo y las necesidades propias. Existe, además, un comité general que se encarga de coordinar las actividades colectivas, de ser el interlocutor entre los manguereros y las instancias externas — como Conagua y otros organismos gubernamentales- y de mediar en situaciones de conflicto entre los distintos grupos. Los integrantes del comité coordinador no reciben retribución económica. 
El sistema de mangueras se desarrolla en un contexto marcado por las limitaciones económicas de los agricultores para acceder a sistemas de riego tecnificado, así como por la falta de concesiones por parte de Conagua; este último hecho restringe o impide que sean beneficiarios de los financiamientos públicos orientados a volver más eficiente el uso del agua. Los agricultores desarrollaron esta forma de gestión del líquido para incorporarse al mercado nacional, sin ayuda del Estado, diversificando sus productos y colocándolos con mucha más fuerza que cuando dependían únicamente del riego de temporal. Así lo expresa uno de los manguereros entrevistados:
Antes — de instalar las mangueras - prácticamente ... vi- víamos del temporal, en tiempos de aguas regábamos ... ahora la gente trae agua en las mangueras para tener un poco más de tiempo cultivando sus tierras, mejorar la calidad de sus cosechas y - prolongar- el tiempo de estar cosechando (entrevista realizada en Tetela del Volcán, Morelos, el 22 de octubre de 2013).

La producción agrícola se incrementó a partir de la adopción del sistema de mangueras. Los agricultores entrevistados describen este hecho como "el desarrollo de la comunidad". "A raíz de las mangueras — dicen — se dio en la comunidad el desarrollo. Gracias al agua Tetela cambió muchísimo.”

$\mathrm{Al}$ igual que la administración y gestión de las cajas de agua, la de las mangueras implica gastos. Según se observó, quienes se responsabilizan de esto son las familias que han contado con cierta autoridad moral y política en la historia reciente de la localidad. Ahora, tanto las mangueras como la capacidad productiva que se deriva de ellas, se concentran en los grupos tradicionales de poder, que son también quienes tienen la solvencia económica.

La cotidianidad organizativa en torno a las mangueras y a las cajas de agua se entrelaza con el sistema tradicional de cargos conformado como se ha dicho, entre otros, por mayordomos, jefes de manzana o de cuadrilla, representantes de grupos, comisariados de bienes comunes 
y ejidales; y coexiste con las instituciones locales, estatales, y federales, producto de la interlegalidad, la cual implica en este caso relaciones asimétricas y un uso estratégico de a quién acudir de acuerdo con cada situación. La asamblea del pueblo valida los acuerdos alcanzados y legitima las reglas en torno al acceso y gestión del agua que los manguereros definen.

En Tetela, al igual que en comunidades cercanas como Hueyapan, el sistema de mangueras comenzó a desarrollarse en los años 80. Anteriormente, el agua para los cultivos provenía de manantiales o escurrimientos trasladada en apancles o rayas, que son canales abiertos en la tierra de forma rudimentaria. El testimonio de un comunero entrevistado también en la localidad, en octubre de 2013, explica a este respecto: "Anteriormente había un tanque grande que nosotros le nombrábamos presa, de ahí el agua venía a flor de tierra por las rayas para regar el trigo. Se hacían rayas y ahí se echaba el agua y ya se regaba hacia la parte baja."

\section{Los límites de la gestión social del agua}

Entre 1920 y 1940 el reparto de tierras permitió a los campesinos de Morelos retomar el control de la producción agrícola y pensar no sólo en el autoconsumo sino también en la agricultura comercial. Sin embargo, como en otras partes del país, el reparto de tierras y agua sobrepasó las posibilidades reales de acceso al agua (De León, 2006). Además, el reconocimiento del acceso al agua fue desigual, a unos pueblos les tocó más que a otros sin razón aparente, y también fue inequitativa al interior de las comunidades, es decir, a unas familias les fue mejor que a otras.

En el caso estudiado observamos que la forma en que se fueron construyendo los sistemas de mangueras generó en esquema muy desigual, débilmente regulado, de acceso y distribución del agua. En este punto hay dos tipos de situaciones conflictivas y de asimetría en el acceso al agua. La primera es la desigualdad interna, la cual se manifiesta en la permanente ampliación y redistribución del agua a más y nuevos usuarios, ubicados en un territorio desigual y montańoso. En un conjunto de grupos estudiados, Boucher (2013) analizó los efectos 
diferenciales del volumen al que acceden los playeros — ubicados en el cauce del río Amatzinac-, los ubicados alrededor del pueblo, y aquellos que han instalado sus mangueras más recientemente aguas arriba, aproximándose al límite norte de las tierras del pueblo. El resultado muestra la existencia de volúmenes muy distintos entre estos grupos, efecto de distintas reglas de distribución a su interior como de su ubicación geográfica.

El otro eje de asimetría es el que se observa con los pueblos vecinos, como Hueyapan, con el cual se tienen fuertes vínculos de parentesco, rituales y organizativos. Es importante señalar que los habitantes de Hueyapan se reconocen como indígenas nahuas, en tanto que los habitantes de Tetela se consideran mestizos, a pesar de conservar una organización comunitaria similar, e incluso más sólida que la de Hueyapan.

Uno de los conflictos más importantes entre las dos comunidades ha sido el originado por la instalación de los sistemas de agua potable en el manantial de Ahueyocan, ubicado en terrenos de Tetela, para abastecer a Hueyapan, hecho que movilizó a las asambleas de ambos pueblos (Guzmán et al., 2012). También ha habido tensiones en torno a las mangueras, que suelen incluir que éstas sean continuamente "macheteadas" por los oponentes. Los conflictos con poblaciones de aguas abajo fueron más intensos en décadas pasadas, tanto que el plan de Conagua para el reordenamiento de la cuenca de Amatzinac tiene como punto de partida la incapacidad institucional de ajustar a los usuarios de la cuenca alta los volúmenes previamente asignados, y tratar, más bien, de administrar la escasez, con nuevas infraestructuras aguas abajo, a partir del pueblo de Tlacotepec, a donde todavía llegan algunas mangueras de la parte alta.

Lo que se resalta al analizar el caso de Tetela es que las normas comunitarias en relación con el uso del agua carecen de visión de largo plazo (Ostrom, 2000), y no consideran el cuidado del recurso en el futuro inmediato. La laxitud de las normas relativas a la pertenencia hace que no exista congruencia entre la disponibilidad de agua y el incremento de los agricultores que requieren riego; a esto hay que sumar la incorporación de cultivos rentables y ampliamente comerciales como el aguacate, que demandan más agua que los cultivos tradicionales 
como son varias hortalizas, chilacayotes y maíz en terrazas, conocidas localmente como besanas, las cuales casi han desaparecido.

Se considera que quien descubre el nacimiento o la fuente donde se instalan las mangueras es quien tiene derecho sobre ella. Pero en la medida en que se incrementaron las mangueras éstas se fueron instalando cada vez más cerca unas de otras y dejó de ser tan claro quién había "descubierto" cada fuente; además, las mangueras colocadas en una posición privilegiada-en un punto más alto, por ejemplologran tomar más agua que otras.

En los últimos años ha surgido la compra/venta de agua, y la renta de mangueras, aun siendo ésta una práctica prohibida pero tolerada. El resultado ha sido la agudización de los conflictos previamente existentes en la comunidad y la profundización de las inequidades sociales. Una entrevistada, con quien se conversó en noviembre de 2014, lo explica así: "Se tienen identificadas personas — para las — que ya es un negocio, pues tienen hasta cinco, seis tomas de agua, entonces rentan a una o dos personas esa agua anualmente". También existen distintos negocios que se hacen con el agua de las cajas y de las mangueras, como el caso de una familia, conocida por todos, que instaló una purificadora de agua proveniente de las cajas, y que la vende embotellada. Un agricultor que tiene la fuente de agua en su terreno "renta" el agua a varios, siendo esto ya su principal ingreso.

En cuanto al funcionamiento de la organización interna, los entrevistados explican que si bien al interior de los grupos logran ponerse de acuerdo, no existe una organización eficaz del conjunto de manguereros. Esto mismo limita la eficacia de cualquier supervisión, de la aplicación de sanciones así como de los mecanismos para la resolución de conflictos. El corte con machete de las mangueras es común, como una forma de desagravio que expresa la lucha difusa y a veces anónima por el agua. Se han suscitado esfuerzos, por parte de la misma comunidad, desde hace por lo menos dos décadas por detener el incremento de las mangueras, pero la organización actual sigue siendo incapaz de lograrlo. Se ha promovido la elaboración de un censo y la creación de una asociación civil de la cuenca alta del río Amatzinac, pero sin un producto efectivo en cuanto a suspender la expansión de 
las mangueras, cada vez más arriba y cercanas al Popocatépetl. Por su parte, la Conagua ha intentado sin éxito regularizar los derechos sobre el agua, implementar una unidad de riego y ordenar la microcuenca (Universidad Autónoma de Chapingo, 2008; Conagua, 2009); no ha podido aun siquiera registrar cuántos son y dónde se encuentran los manguereros.

\section{Conclusiones}

La caracterización del Estado mexicano como el único capaz de producir normas y procedimientos jurídicos legítimos en torno al agua está siendo cuestionada por la enorme diversidad de experiencias, culturalmente marcadas, de gestión local. Los enfoques estatistas se concentraron en dar cuenta de las políticas de desarrollo y sus vínculos con los recursos hídricos, así como de sus efectos sobre las poblaciones receptoras o afectadas. A partir de la crisis del modelo de gestión centralizada del agua, y la vuelta hacia un modelo descentralizado por cuenca hidrológica, en el cual se reconoce — aunque de manera limitada y fuertemente controlada_-, la participación de los "usuarios del agua” a través de una representación corporativa. Las formas de autogestión del agua para riego y abastecimiento de agua potable empiezan a ser también del interés de académicos y de formuladores de políticas públicas, para los primeros como una muestra de que sí es posible convivir con la naturaleza y para los segundos con el objetivo de ordenar y regular los usos del agua o "garantizar" el acceso al agua como meta de política pública.

Existe una larga tradición en las comunidades campesinas e indígenas de gestión y manejo del agua potable y para riego. La incapacidad de los gobiernos para satisfacer la totalidad de la demanda del líquido ha llevado a que las comunidades se responsabilicen de su propio abastecimiento, muchas veces, recurriendo a sus formas de organización comunitaria tradicional, que rigen también el trabajo y la distribución de derechos y obligaciones. Sobre dicha organización social se tejen una serie de relaciones que dan sustento a la propiedad corporada de un territorio, importante elemento de lo comunitario y fundamento de los mecanismos que excluyen a los extraños y rigen el acceso al patrimonio común. 
La coexistencia de distintos sistemas normativos en torno al agua, en el caso de Tetela, el oficial y el local, implica su interacción en distintos escenarios: de autonomía o dominación, de vinculación y articulación negociada, de oposición, de influencia mutua. El mismo autoritarismo y centralización mostrados por el Estado en otros aspectos, como el riego y en menor medida la administración del agua potable, evidencia su debilidad ante los marcos normativos locales, así como su desigual capacidad de actuación a nivel nacional en relación con los órdenes políticos locales.

El caso de Tetela del Volcán es una expresión de la pluralidad de formas de gestión del agua. Se trata de un pueblo que se asume mestizo y que posee una organización social similar a otros pueblos campesinos e incluso indígenas de México: organización de barrios, una asamblea del pueblo que en ocasiones tiene mayor peso político que el mismo gobierno municipal, un ciclo ritual y de cargos vinculados con el acceso a la tierra, agua y bosque. Esto también se expresa en un conjunto de representaciones sociales respecto al agua en su territorio.

En contradicción con las reconstrucciones de algunos académicos y activistas, de las prácticas agrícolas campesinas tradicionales como intrínsecamente ecológicas, expresando que tienden a implementar y gestionar sistemas ecológicos como un nuevo paradigma científico (i.e. Toledo, 2008), la expansión de los sistemas de riego y agua potable en Tetela del Volcán parece estar llevando la gestión comunitaria a sus límites; la organización local no ha logrado actualizar sus normas y adecuarlas al nuevo contexto de expansión de una agricultura más vinculada al mercado, ni resolver viejos conflictos o lidiar con factores centrales como los efectos diferenciadores, en términos económicos, políticos y sociales, del uso de las mangueras.

El agua es considerada una mercancía por algunos agricultores. Para otros es un bien público que debe ser administrado por el Estado, o al menos aceptan la intervención gubernamental vía el financiamiento de nuevas tecnologías agrícolas o de riego que les permita seguir y ampliar su producción para el mercado. Para otros más, funciona como un recurso de uso común que debe ser preservado por la organización comunitaria. Estas tres comprensiones con frecuencia coexisten y se manifiestan de 
forma simultánea; así ocurre en el caso de Tetela del Volcán. El Estado ha logrado penetrar hasta cierto punto en la administración del agua, pero muchas prácticas, quizá las más importantes por su magnitud y peso económico, escapan a la contabilidad gubernamental e incluso a su vigilancia. Es el caso del sistema de riego por mangueras del cual todos los niveles de gobierno tienen noticia, pero ninguno cuenta con datos precisos y mucho menos inciden en su funcionamiento, a pesar de múltiples esfuerzos por organizarlos como una unidad de riego bajo la figura de asociación civil y ofrecerles infraestructura y regularizarlos con un título de concesión, bajo el cual los agricultores serían vigilados por la Conagua (Conagua, 2009; La Unión de Cuautla, 10 de febrero de 2010). El agua funciona, en el sistema de mangueras, como un recurso de uso común administrado por los agricultores, pero al mismo tiempo es visto por ellos mismos como un insumo productivo que pueden comprar y vender con el más puro espíritu capitalista, pero sólo entre ellos.

El agua como bien social cumple funciones más complejas que su uso para la reproducción material. En muchos casos delimita un espacio, define un territorio donde se dan las relaciones sociales. En los pobladores de Tetela, como en muchos otros grupos culturales, la relación con los cuerpos de agua de la zona ha sido fundamental para la construcción de su identidad cultural y de su historia; esta relación ha definido sus fronteras sociales, sus formas de organización, y se encuentra muy presente en su forma de entender el mundo.

\section{Bibliografía citada}

Aguilera Klink, F., 1988, "El agua como recurso de propiedad común: una perspectiva económica”, Estudios Regionales, núm. 20, pp. 17-32.

Aguilera Klink, F., 1995, "El agua como activo social", en José A. González y A. Malpica (coordinadores), El Agua. Mitos, ritos y realidades, Ed. Anthropos, Barcelona.

Arias, Patricia y Lucía Bazán, 1979, Demandas y conflicto (El poder político en un pueblo de Morelos), Nueva Imagen/CIS-INAH, México. 
Ávila, Patricia, 1996, Escasez de agua en una región indigena: el caso de la Meseta Purépecha, El Colegio de Michoacán, Zamora, Mich. Ávila, Patricia, 2007, El manejo del agua en territorios indígenas en México, Banco Mundial, Departamento de México y Colombia, Región de Latinoamérica y el Caribe, México D.F. (Serie del Agua en México, vol. 4).

Boelens, R., G. Dávila, 1998, Buscando la equidad. Concepciones sobre justicia y equidad en el riego campesino, Van Gorcum, Assen, Países Bajos.

Boelens, R., M. Zwarteveen, D. Roth, 2005, "Legal complexity in the analysis of water rights and water resources management", en Roth, D., R. Boelens, M. Zwarteveen (editores), Liquid Relations. Contested water rights and legal complexity, Rutgers University Press, New Jersey, pp. 1-19.

Boucher, Luc, 2013, Conflits liés à l'eau dans le bassin versant de la rivière Amatzinac. Cas du village de Tetela del Volcàn, Morelos, Mexico, Memoire de fin d'etudes, Ecole Supérieure d'Agro-Développement International, ISTOM, Cergy-Pontoise, Francia.

Comisión Nacional del Agua, 2009, El río Amatzinac: Ciclos de vida, Semarnat, México.

De León, Arturo, 2006, "Acceso al agua, conflictos y construcción social de los pueblos de la Barranca del Amatzinac, Morelos", en Canabal Beatriz, Gabriela Contreras et al., Diversidad Rural. Estrategias económicas y procesos culturales, UAM-X/Plaza y Valdez, México.

Ennis-McMillan, Michael C., 2001, La Purificación Tepetitla. Agua potable y cambio social en el Somontano, Universidad Iberoamericana-Archivo Histórico del Agua, Colección Tepetlaoxtoc, núm. 7, México.

Espinosa, Oscar M., 2005, Sociedad y agua en Zacualpan de Amilpas, CEDRSSA, México.

Estrada, Arturo y Hugo Franco, 2004, “Entre la ley y la costumbre: El uso y manejo del agua potable en el municipio de Temoaya, Estado de México", Páramo del campo y la ciudad, núm. 7, 
diciembre, Centro de estudios sobre marginación y pobreza del Estado de México, Toluca, México.

Galindo-Escamilla, Emmanuel y Jacinta Palerm-Viqueira, 2007,

"Pequeños sistemas de agua potable: entre la autogestión y el manejo municipal en el estado de Hidalgo, México", Agricultura, Sociedad y Desarrollo, vol. 4, núm. 2, juliodiciembre, El Colegio de Posgraduados, México.

Gall, Olivia, 2001, "Estado federal y grupos de poder regionales frente al indigenismo, el mestizaje y el discurso multiculturalista: pasado y presente del racismo en México", Debate Feminista, año 12, vol. 24.

Guzmán Ramírez N. B., 2010, "Las juntas de agua, una forma de organización de gestión social del agua impuesta desde el centro", en Daniel Murillo y Jacinta Palerm (editores), Memorias I Congreso Red Investigadores Sociales Sobre Agua, Instituto Mexicano de Tecnología del Agua, Jiutepec, México.

Guzmán Ramírez, N. B., M. Reyes Quintero, A. Pérez Rodríguez, L. González Flores, 2012, "Agua y territorio comunitario: Tetela del Volcán vs. Hueyapan”, en Vargas, S., Eric Mollard, Alfonso Güitrón de los Reyes (coordinadores), Los conflictos por el agua en México: caracterización y prospectiva, Conamexphi/IMTA/ UAEM, México.

Hale, Charles, 2006, More than an indian. Racial ambivalence and neoliberal multiculturalism in Guatemala, School of American Research Press, USA.

Hernández Castillo, Aída, 1995, "Invención de tradiciones: encuentros y desencuentros de la población mame con el indigenismo mexicano", América Indígena, 1-2.

López-Villamar, Sara M., Tomás Martínez-Saldaña, Jacinta PalermViqueira, 2013, "Las comunidades en la administración de sistemas de agua potable: región de los volcanes, estado de México", Agricultura, Sociedad y Desarrollo, vol. 10, núm. 1, enero-marzo, El Colegio de Posgraduados, México. 
Martínez Saldaña, Tomas, 2007, "El uso del riego ancestral en la agricultura contemporánea, el caso de los sistemas de riego en el árido mexicano", Taller Modernización de Riegos y Uso de Tecnologias de Información, Red Riegos CYTED/Instituto Interamericano de Cooperación para la Agricultura, La Paz, Bolivia, en http://ceer.isa.utl.pt/cyted/2007/bolivia2007

Moreno Vázquez, José Luis, 2014, Despojo de agua en la cuenca del río Yaqui, El Colegio de Sonora, Hermosillo, México.

Ostrom, Elinor, 2000, El gobierno de los bienes comunes. La evolución de las instituciones de acción colectiva, Fondo de Cultura Económica/CRIM UNAM, México.

Palerm Viqueira, Jacinta, 2005, "Gobierno y administración de sistemas de riego", Región y Sociedad, vol. XVII, núm. 34.

Palerm Viqueira, Jacinta y María Rivas, 2005, “Organización social y riego”, Nueva Antropología. Revista de Ciencias Sociales, núm. 64.

Palerm Viqueira, Jacinta, y Tomás Martínez Saldaña, 2007, "Antropología del regadío", Taller Modernización de Riegos y Uso de Tecnologías de Información, Red Riegos CYTED/Instituto Interamericano de Cooperación para la Agricultura, La Paz, Bolivia, en http://ceer.isa.utl.pt/cyted/2007/bolivia2007

Rendón Monzón, Juan José, 2003, La comunalidad. Modo de vida en los pueblos indios, Conaculta, México.

Reyes Quintero, Martha Shirley, 2011, La organización local y los Recursos de Uso Común en Tetela del Volcán. Actores, espacios de decisión y sistemas de gobierno, tesis de maestría en Instituciones y Organizaciones, Universidad Autónoma del Estado de Morelos, México.

Rodríguez Rojo, Alma Rosa, 1995, San Juan Tezontla. Lucha por el agua, Universidad Iberoamericana/Archivo Histórico del Agua, Colección Tepetlaostoc, núm. 7, México.

Sandoval-Moreno, Adriana, 2011, "Entre el manejo comunitario y gubernamental del agua en la Ciénega de Chapala, Michoacán, México", Agricultura, Sociedad y Desarrollo, vol. 8, núm. 3, septiembre-diciembre, El Colegio de Posgraduados, México. 
Toledo, Víctor M., Narciso Barrera-Bassols, 2008, La memoria biocultural. La importancia ecológica de las sabidurías tradicionales, Icaria, Barcelona.

UACH-Conagua, 2008, Formulación del Plan Director y del inventario de la infraestructura, integración del padrón de usuarios y de los planos parcelarios y elaboración del reglamento de las unidades de riego que se abastecen de la Barranca de Amatzinac del Estado de Morelos. Informe final descriptivo, Universidad Autónoma de Chapingo/Conagua, Convenio de colaboración SGIH-OCBUACH-MOR-08-MD-115-RF-CC, México.

Valladares, Laura, 2003, Cuando el agua se esfumó. Cambios y continuidades en los usos sociales del agua en Morelos. 1880-1940, UNAM, México, D.F.

Vargas, Sergio, 2001, "Conflictos por el agua en la cuenca del río Amatzinac, en el oriente de Morelos", en Melville Roberto y Claudia Cirelli (editores), Cambio, organización y conflicto: El horizonte social del agua para el siglo XXI, [CD-ROM] El Colegio de San Luis, CIESAS, México D.F.

\section{Nota hemerográfica}

La Unión de Cuautla, "Firman acuerdo histórico usuarios de la barranca Amatzinac", 10 febrero de 2010, en http://www.launion. com.mx/morelos/cuautla/noticias/2627-firman-acuerdohist $\% \mathrm{C} 3 \% \mathrm{~B} 3$ rico-usuarios-de-la-barranca-amatzinac.html 